\title{
Unrecognized impact of a biocontrol agent on the spread rate of an invasive thistle
}

\author{
Katherine M. Marchetto, ${ }^{1,5,6}$ Katriona Shea, ${ }^{1}$ Dave Kelly, ${ }^{2}$ Ronny Groenteman, ${ }^{3}$ Zeynep Sezen, ${ }^{1,7}$ \\ and EelKe Jongejans ${ }^{4}$ \\ ${ }^{1}$ Department of Biology and IGDP in Ecology, 208 Mueller Laboratory, Pennsylvania State University, University Park, \\ Pennsylvania 16802 USA \\ ${ }^{2}$ School of Biological Sciences, University of Canterbury, Private Bag 4800, Christchurch, New Zealand \\ ${ }^{3}$ Landcare Research, P.O. Box 69040, Lincoln 7640 New Zealand \\ ${ }^{4}$ Radboud University Nijmegen, Institute for Water and Wetland Research, Animal Ecology and Ecophysiology, P.O. Box 9100, \\ 6500 GL Nijmegen, The Netherlands
}

\begin{abstract}
Herbivores may significantly reduce plant populations by reducing seed set; however, we know little of their impact on seed movement. We show for the first time that the receptacle-feeding weevil Rhinocyllus conicus not only reduces seed production by the invasive thistle Carduus nutans but also inhibits release and subsequent wind dispersal of seeds. These effects generate large, though different, impacts on spatial spread and local abundance in two populations with differing demography, located in the United States and New Zealand. Furthermore, the mechanism is context dependent, with the largest effects through increased terminal velocity in the United States but through reduced seed production in New Zealand. Our results show that the benefit of biocontrol programs may have been underestimated; screenings of potential biocontrol agents should examine effects on pest dispersal and spread, as well as on abundance.
\end{abstract}

Key words: biological control; Carduus nutans; context-dependent management; introduced weevil; plant-insect interactions; Rhinocyllus conicus; spread rate modeling; wind dispersal.

\section{INTRODUCTION}

Herbivory can reduce plant fitness and population abundance (Maron and Crone 2006, Kolb et al. 2007). However, our understanding of how herbivores affect plant spatial dynamics has focused on how herbivory decreases seed production, causing fewer seeds to travel to new locations (Kelly and McCallum 1995, Fagan et al. 2005, Vellend et al. 2006, Le Maitre et al. 2008). The effects of antagonistic herbivores on seed movement are rarely studied, and work focuses on damage that causes fruits to be less attractive to animal seed dispersers (Borowicz 1988, Vivian-Smith et al. 2006). Little is known about how herbivores affect the efficacy of other seed dispersal strategies, such as dispersal by wind.

An explicit understanding of the direct effects of herbivores on plant dispersal is important for several reasons. Levels of herbivory will be higher if reduced dispersal allows herbivores to find more plants (Swamy and Terborgh 2010). Ignoring the effects of herbivores

Manuscript received 8 July 2013; revised 18 November 2013; accepted 26 November 2013; final version received 17 December 2013. Corresponding Editor: A. K. Brody.

${ }^{5}$ E-mail: kmm388@cornell.edu

${ }^{6}$ Present address: Department of Ecology and Evolutionary Biology, A408 Corson Hall, Cornell University, Ithaca, New York 14850 USA.

7 Present address: Department of Entomology, University of Minnesota, 1980 Folwell Avenue, St. Paul, Minnesota 55108 USA. on seed movement in plant spread models could reduce the accuracy of predictions of plant metapopulation dynamics, invasion by nonnative species, and the ability of species to shift their ranges due to climate change. These errors would have further repercussions at the community level, as movement of species into previously unoccupied areas affects community assembly and network structure (Vilà et al. 2009).

A deeper understanding is vital for applied ecology also. The application of biological control focuses almost entirely on reductions in invasive plant abundance rather than spread (Debach 1974, Waage and Mills 1992, Eilenberg et al. 2001, Coombs et al. 2004, but see Vivian-Smith et al. 2006). While managing for abundance can reduce spread rates through a reduction in the number of dispersing individuals (Kelly and McCallum 1995, Le Maitre et al. 2008), focusing on strategies that directly target dispersal mechanisms is more likely to successfully reduce spread rates (Shea et al. 2010, Coutts et al. 2011). Biological control is usually used in situations where an invader has already become widespread (Delfosse 2005); however, distributions are often locally patchy (Allen and Shea 2006) and reducing dispersal can lower control costs by reducing the area that must be searched for outlying plants.

Anecdotal evidence suggests that some herbivores have direct effects on seed dispersal by wind (Shorthouse and Lalonde 1984, Smith and Kok 1984, Coombs et al. 2004). For example, many biocontrol agents reduce the 
height of their hosts (Coombs et al. 2004). The effect of reduced height on seed dispersal distances can be remarkably strong (Jongejans et al. 2008), stronger than the effect of seed mass in many cases (Thomson et al. 2011). In addition, several biocontrol agents of invasive plants in the family Asteraceae potentially reduce seed release and movement through floral feeding (Coombs et al. 2004). Urophora solstitialis (Diptera: Tephritidae) and Metzneria paucipunctella (Lepidoptera: Gelechiidae) bind seeds together in the capitulum, while Larinus minutus and L. obtusus (Coleoptera: Curculionidae) feed on the wind dispersal structures (Coombs et al. 2004). Despite the implications for seed movement and population spread, only height effects have been quantified and there has been no direct measurement or modeling of any resulting effects on seed dispersal and spread.

We here provide the first detailed quantification of a direct effect of herbivore receptacle feeding on the dispersal of a wind-dispersed plant, Carduus nutans (Asteraceae). Rhinocyllus conicus (Froelich; Coleoptera: Curculionidae) larvae feed in the $C$. nutans receptacle and induce callus tissue, which may interfere with seed release (Shorthouse and Lalonde 1984, Smith and Kok 1984). Shorter than average wind dispersal structures (pappi) have also been observed in heavily attacked capitula (Shorthouse and Lalonde 1984). We hypothesize that $R$. conicus damage has hierarchical effects that reduce $C$. nutans spread rates via: (1) lower $C$. nutans seed production (Surles and Kok 1978), (2) lower probability of seed release, and (3) decreased dispersal capacity of released seeds. To test these hypotheses, capitula with a range of damage by $R$. conicus larvae were collected from naturalized populations of $C$. nutans. Seed release was quantified under realistic conditions in a wind tunnel, followed by capitulum dissections and seed terminal velocity measurements. These empirical data were used to project reductions in spread rates caused by a range of weevil damage for two populations with differing demography and average weevil attack rates in the invaded range of $C$. nutans where $R$. conicus has previously been introduced as a biocontrol agent: an experimental population of $C$. nutans in the United States of America (USA) and a natural population in New Zealand.

\section{Materials And Methods}

\section{Study species}

Carduus nutans is a thistle species of Eurasian origin that is an invasive weed in many areas, including North America and New Zealand (Kelly and Popay 1985, Desrochers et al. 1988). C. nutans is a monocarpic perennial that reproduces exclusively by seed (Desrochers et al. 1988). Individual capitula contain in the range of 165-256 seeds (Desrochers et al. 1988), and up to 400 seeds (Sezen 2007).

Rhinocyllus conicus was first released as a biocontrol agent for $C$. nutans and other related thistle species in the United States in 1969 (Gassmann and Louda 2001) and in New Zealand in 1972 (Jessep 1989). R. conicus oviposits on the undersides of flower buds (Shorthouse and Lalonde 1984). Emerging larvae chew into the receptacle and may feed close to the ovules or between the upper and central receptacle (Shorthouse and Lalonde 1984; see Plate 1). Both feeding strategies sever vascular bundles and induce the formation of callus tissue (Shorthouse and Lalonde 1984). Each larva eventually forms a larval chamber (cyst) where it pupates (Shorthouse and Lalonde 1984). The callus tissue formed by larval feeding is visible as hardened, blackened tissue inside capitula that are ready to disperse seeds. The pappus filaments of attacked capitula have also been observed to be shorter than those of unattacked capitula (Shorthouse and Lalonde 1984).

\section{Capitulum collection}

We haphazardly collected $146 C$. nutans capitula with a natural range of attack by $R$. conicus from no damage to heavy damage (based on observable egg case load). Capitula were placed in individual paper bags when seeds were mature (but before any dispersal) so the total number of seeds produced by each capitulum could be quantified. Collections were on three dates between 15 and 25 July 2007 from three naturalized populations in central Pennsylvania, USA.

\section{Wind tunnel trials}

Capitula were evaluated for seed release in a closedcircuit wind tunnel in Pennsylvania State University's Aerospace Engineering Department with a test section $90 \mathrm{~cm}$ high, $60 \mathrm{~cm}$ wide, and $6 \mathrm{~m}$ long (see also Skarpaas et al. 2006, Jongejans et al. 2007). Laminar flow, as produced in wind tunnels, is very rare in nature, while increased turbulence is known to increase seed release (Skarpaas et al. 2006, Jongejans et al. 2007). Therefore, turbulence was created by a frame holding a single threaded rod of $1.5 \mathrm{~cm}$ diameter at capitulum height (Marchetto et al. 2012). Wind speeds generated by the tunnel were calibrated by taking into account daily air temperatures and pressures, as well as airflow resistance caused by the frame holding the threaded rod and by a downwind screen used to trap dispersing seeds.

Capitula were allowed to dry in closed paper bags for several days before use in wind tunnel trials, to promote seed release (Jongejans et al. 2007, Marchetto et al. 2012). After drying, capitula were attached one at a time to a stiff, $1.1 \mathrm{~cm}$ diameter metal rod, centered at a height of $46 \mathrm{~cm}$ in the middle of the wind tunnel, to minimize any wall effects. Seeds released in bags prior to the wind tunnel trials were quantified. Each wind tunnel trial was conducted at a wind speed of $6 \mathrm{~m} / \mathrm{s}$ for one minute. Released seeds were caught in a 1.6- $\mathrm{mm}$ mesh fiberglass screen downwind, removed after each trial, and counted. Only seeds that appeared to contain viable embryos were recorded. 


\section{Terminal velocity measurements and dissections}

Seeds from the capitula used in wind tunnel trials were measured for terminal velocity values. A maximum of 10 seeds with attached pappi were randomly selected from each capitulum. The terminal velocity of each was determined by measuring the time it took to drop through an enclosed cardboard tube with a height of $1.17 \mathrm{~m}$ and an internal diameter of $7.48 \mathrm{~cm}$. Plumed Asteraceae seeds reach terminal velocity quickly (Sheldon and Burrows 1973), so timing began after seeds had dropped through a clear $10-\mathrm{cm}$ plastic shield at the top of the tube to allow seeds to reach terminal velocity. The terminal velocity tube had two clear plastic windows near the bottom for illumination and viewing. Each seed was dropped until two drop times were within 0.1 second, and these values were averaged. This usually only took two drops. Terminal velocity was calculated as the length of the tube divided by the average drop time.

Pappus width, maximum pappus filament length, and seed mass were recorded for all terminal velocity trial seeds. Plume area calculation assumed that the pappus is a circular cone with a base area determined by the measured pappus diameter (Meyer and Carlson 2001).

Finally, each capitulum was dissected. Capitulum diameter, number of available dispersal units (seeds with attached pappi), number of seeds free of the receptacle, and number of seeds trapped in the receptacle were recorded. Trapped seeds remained fixed in capitulum receptacles after manual removal of loose seeds, a process designed to simulate the action of the wind throughout the dispersal season. Egg cases and cysts were counted to quantify weevil attack.

\section{Statistical analysis}

The reduction in seed production by $R$. conicus damage was related to number of cysts and capitulum diameter using generalized linear models (GLMs) with Poisson error distributions and correction for overdispersion. Capitulum diameter was included in the models because $R$. conicus attack rates are higher on larger capitula, but large unattacked capitula produce more seeds (Sezen 2007). All statistical analyses were done in R 2.10.1 (R Development Core Team 2012).

The seed release data were treated as binomial success/failure data in two separate analyses. In the first analysis we measured the chance of a seed remaining in the capitulum during the wind tunnel trial; in the second, we measured the chance of a seed remaining in the capitulum after manual removal of loose seeds during dissection. Initial data analysis used generalized linear mixed-effects models (LMER) with population and collection date as nested random variables. Random variable structure was determined using likelihood ratio tests to compare full and reduced models (Crawley 2007). If neither random variable provided a significantly better fit to the data, the data were then analyzed using GLMs with binomial error distributions.
Linear mixed-effects models (LME) were used to analyze the effects of cysts on terminal velocity with number of cysts as a fixed effect and population, collection date, and source capitulum as random effects. The terminal velocity data were log-transformed, and the best-fit model was determined using likelihood ratio tests to compare full and reduced models (Crawley 2007). Wing loading was calculated to assess which seed characteristics had an effect on terminal velocity values. Wing loading (seed mass divided by plume area) is a significant predictor of log-transformed terminal velocity (Greene and Johnson 1990). The relationships between number of cysts and log-transformed wing loading, pappus area, and seed mass were examined using GLMs.

\section{Spread rate modeling}

Population spread rates including the effects of $R$. conicus cysts on seed production, release, and terminal velocity were determined for two populations of $C$. nutans with different plant demography, one in the United States and one in New Zealand. Spread rates were projected using coupled integrodifference models, which allow the calculation of a traveling wave speed, $c^{*}$, for a species invading a homogenous landscape (Neubert and Caswell 2000, Jongejans et al. 2008). Two components are used to calculate the spread rate, a population projection matrix (A), and a matrix (M) containing the moment-generating function for each dispersive stage. The $c^{*}$ calculation methods of Jongejans et al. (2008) were modified to include a new population projection matrix which tracks the fates of plants derived from seeds that are not released from the parent plant, stochastic seedling establishment probabilities, and functions for the effects of a range of weevil damage on seed production, release, and terminal velocity. Full modeling details are given in Appendix A.

A $12 \times 12$ matrix was developed based on the $4 \times 4$ stage-structured matrix of Shea and Kelly (1998) and the $7 \times 7$ matrix used by Jongejans et al. (2008) to include information concerning reductions in seed release caused by cysts (Eq. 1). The four main stages are seed bank (SB), small $(\mathrm{S})$, medium $(\mathrm{M})$, and large (L) rosettes, each divided into three substages: individuals derived from dispersing seeds (D), individuals derived from nondispersing seeds (ND), and locally surviving individuals (LS). The order of the rows in Eq. 1 corresponds to SBD, SB-ND, SB-LS, S-D, S-ND, S-LS, M-D, M-ND, MLS, L-D, L-ND, and L-LS from top to bottom. Nondispersing seeds are those that were embedded in capitulum tissue. Parameter definitions are given in Table 1. Seedling establishment probabilities were drawn from beta distributions that included realistic ranges of values from empirical data reported in Peterson-Smith and Shea (2010). All three substage columns are calculated using the same formulae, so only one column is shown for each main stage class. The dominant eigenvalue of this matrix is the asymptotic population growth rate (Neubert and Caswell 2000). 
TABLE 1. Definitions and values for terms given in Eq. 1 for an experimental population of Carduus nutans in Pennsylvania, USA, and a natural population in Midland Road, New Zealand.

\begin{tabular}{llcc}
\hline \hline \multicolumn{1}{c}{ Stage and parameter } & Term & USA & NZ \\
\hline A) Stage class borders & & & \\
Between S and M $\left(\mathrm{cm}^{2}\right)$ & & 16.6 & 83.1 \\
Between M and L $\left(\mathrm{cm}^{2}\right)$ & & & 175 \\
B) Demographic parameters & & & \\
Survival of seed in SB & $\sigma_{1}$ & 0.2597 & 0.0382 \\
Survival of S & $\sigma_{2}$ & 0.2619 & 0.1164 \\
Survival of M & $\sigma_{3}$ & 0.6761 & 0.6813 \\
Survival of L & $\sigma_{4}$ & 0.8971 & 0.7532 \\
Growth of establishing seed to M & $\gamma_{3}$ & 0.2076 & 0 \\
Growth of establishing seed to L & $\gamma_{4}$ & 0.0911 & 0 \\
Growth of surviving, not bolting S to M & $\gamma_{32}$ & 0.8028 & 0.1065 \\
Growth of surviving, not bolting S to L & $\gamma_{42}$ & 0.1268 & 0.0651 \\
Retrogression of surviving, not bolting M to S & $\rho_{23}$ & 0 & 0.3333 \\
Growth of surviving, not bolting M to L & $\gamma_{43}$ & 0.3824 & 0.6667 \\
Retrogression of surviving, not bolting L to S & $\rho_{24}$ & 0 & 1 \\
Retrogression of surviving, not bolting L to M & $\rho_{34}$ & 0 & 0 \\
Bolting of surviving S & $\beta_{2}$ & 0.1932 & 0.262 \\
Bolting of surviving M & $\beta_{3}$ & 0.7143 & 0.9516 \\
Bolting of surviving L & $\beta_{4}$ & 1 & 0.9828 \\
Potential seed production by S & $\pi_{2}$ & 5443 & 2437 \\
Potential seed production by M & $\pi_{3}$ & 6150 & 2776 \\
Potential seed production by L & $\pi_{4}$ & 12446 & 3576 \\
Potential seed escaping from floral herbivory & $\varphi$ & $0.3238 \dagger$ & $0.6952 \dagger$ \\
New seed entering SB & $\mathrm{v}$ & 0.2333 & 0.157 \\
New seed establishing seedling & $\varepsilon$ & mean $0.2333 \ddagger$ & mean $0.0194 \S$ \\
Seed from SB establishing seedling & $\varepsilon_{1}$ & mean $0.2333 \ddagger$ & mean $0.1847 \S$ \\
Proportion of seeds that disperse & $\delta$ & $0.8148 \dagger$ & $0.9041 \dagger$ \\
\hline
\end{tabular}

Notes: The four main stages are seed bank (SB), small (S), medium (M), and large (L) rosettes. Parameters in italics were estimated from a different population (for details, see Jongejans et al. 2008). Seedling establishment rates for both populations (USA and New Zealand) were chosen from beta distributions.

$\dagger$ Parameter values that are described as a function of average cysts per capitulum; values are given for the average number of cysts for each population. 11.5.

$\$$ Seedling establishment rates for the U.S. population had mean 0.2333 , alpha 3.5 , and beta

$\S$ Seedling establishment rates for the N.Z. population had mean 0.0194 , alpha 0.012 , and beta 0.607 for new seeds and mean 0.1847 , alpha 1.8 , and beta 9.665 for seeds from the seed bank.

$$
\left(\begin{array}{cc}
\text { SB } & \text { Small } \\
0 & \sigma_{2} \beta_{2} \pi_{2} \varphi v \delta \\
0 & \sigma_{2} \beta_{2} \pi_{2} \varphi v(1-\delta) \\
\sigma_{1} & 0 \\
0 & \sigma_{2} \beta_{2} \pi_{2} \varphi \varepsilon\left(1-\gamma_{3}-\gamma_{4}\right) \delta \\
0 & \sigma_{2} \beta_{2} \pi_{2} \varphi \varepsilon\left(1-\gamma_{3}-\gamma_{4}\right)(1-\delta) \\
\varepsilon_{1}\left(1-\gamma_{3}-\gamma_{4}\right) & \sigma_{2}\left(1-\beta_{2}\right)\left(1-\gamma_{32}-\gamma_{42}\right) \\
0 & \sigma_{2} \beta_{2} \pi_{2} \varphi \varepsilon \gamma_{3} \delta \\
0 & \sigma_{2} \beta_{2} \pi_{2} \varphi \varepsilon \gamma_{3}(1-\delta) \\
\varepsilon_{1} \gamma_{3} & \sigma_{2}\left(1-\beta_{2}\right) \gamma_{32} \\
0 & \sigma_{2} \beta_{2} \pi_{2} \varphi \varepsilon \gamma_{4} \delta \\
0 & \sigma_{2} \beta_{2} \pi_{2} \varphi \varepsilon \gamma_{4}(1-\delta) \\
\varepsilon_{1} \gamma_{4} & \sigma_{2}\left(1-\beta_{2}\right) \gamma_{42}
\end{array}\right.
$$

$$
\begin{gathered}
\text { Large } \\
\sigma_{4} \beta_{4} \pi_{4} \varphi v \delta \\
\sigma_{4} \beta_{4} \pi_{4} \varphi v(1-\delta) \\
0 \\
\sigma_{4} \beta_{4} \pi_{4} \varphi \varepsilon\left(1-\gamma_{3}-\gamma_{4}\right) \delta \\
\sigma_{4} \beta_{4} \pi_{4} \varphi \varepsilon\left(1-\gamma_{3}-\gamma_{4}\right)(1-\delta) \\
\sigma_{4}\left(1-\beta_{4}\right) \rho_{24} \\
\sigma_{4} \beta_{4} \pi_{4} \varphi \varepsilon \gamma_{3} \delta \\
\sigma_{4} \beta_{4} \pi_{4} \varphi \varepsilon \gamma_{3}(1-\delta) \\
\sigma_{4}\left(1-\beta_{4}\right) \rho_{34} \\
\sigma_{4} \beta_{4} \pi_{4} \varphi \varepsilon \gamma_{4} \delta \\
\sigma_{4} \beta_{4} \pi_{4} \varphi \varepsilon \gamma_{4}(1-\delta) \\
\sigma_{4}\left(1-\beta_{4}\right)\left(1-\rho_{24}-\rho_{34}\right)
\end{gathered}
$$

Demographic vital rates for the generation of population projection models came from an experimental population of $C$. nutans from Pennsylvania, USA, and a naturalized $C$. nutans population along Midland Road near Ashhurst, New Zealand (Jongejans et al. 2008). The U.S. experiment provided vital rates for plants growing under ideal conditions of low competition (K. Shea, unpublished data 2002-2005). This experiment is described in detail in Jongejans et al. (2008).

Population growth rates were calculated for the U.S. and N.Z. populations with a range of average cysts from 
TABLE 2. Fixed effects describing the relationships between seed release and dispersal characteristics and the number of Rhinocyllus conicus cysts per capitulum for Carduus nutans collected from naturalized populations in the United States.

\begin{tabular}{llrrrr}
\hline \hline \multicolumn{1}{c}{ Parameter } & \multicolumn{1}{c}{ Fixed effect } & $\begin{array}{c}\text { Sample } \\
\text { size }\end{array}$ & Estimate & SE & \multicolumn{1}{c}{$P$} \\
\hline Seed production $\dagger$ & number of cysts & 146 & -0.161 & 0.024 & $\ll 0.001$ \\
& capitulum diameter & 146 & 0.025 & 0.014 & 0.070 \\
Seed release $\ddagger$ & number of cysts & 146 & -0.085 & 0.012 & $\ll 0.001$ \\
Seeds trapped in capitulum $\ddagger$ & number of cysts & 146 & 0.169 & 0.006 & $\ll 0.001$ \\
Terminal velocity§ & number of cysts & 690 & 0.042 & 0.007 & $\ll 0.001$ \\
\hline $\begin{array}{l}\dagger \text { Poisson GLM with overdispersion correction. } \\
\text { † Binomial GLM. }\end{array}$ & & & & \\
§ Log-transformed terminal velocity LME with capitulum of origin as a random effect. \\
Capitulum explained 48.96\% of the variance. In the case of terminal velocity, the sample size is the \\
number of seeds nested within the capitulum.
\end{tabular}

0 to 15 , under the assumption that $R$. conicus damage has the same effect on N.Z. capitula of the same size. The proportion of seeds escaping from floral herbivory $(\varphi)$ was calculated from the fitted model for the effect of number of cysts and average capitulum diameter on the number of seeds produced per capitulum (Table 2). Average capitulum diameters are $34.5 \mathrm{~mm}$ for the U.S. population and $14.7 \mathrm{~mm}$ for the N.Z. population. Capitulum diameter was retained in the model for seed production because the effect of capitulum diameter on seed production was found to be significant with larger data sets (Kelly et al. 1990, Sezen 2007). Proportions of nondispersing seeds for a range of $R$. conicus cysts came from a statistical model of the number of seeds trapped in $C$. nutans flower receptacles, which failed to release before, during, or after wind tunnel trials and remained after all loose seeds were manually removed from capitula. The proportion of seeds that disperse $(\delta)$ was calculated as 1 minus the fitted model for the proportion of seeds trapped in the capitulum as a function of cysts.

The moment-generating function used a seasonally integrated dispersal kernel calculated using the Wald analytical long-distance dispersal (WALD) model of Jongejans et al. (2008), which gives a good fit to dispersal data from $C$. nutans (Skarpaas and Shea 2007). The WALD model uses wind speed, a wind instability parameter, terminal velocity, and seed release height to determine a dispersal kernel (Katul et al. 2005). Hourly wind speed measurements were collected from State College, Pennsylvania, USA during July and August 1999-2006. Wind speed at seed release height was calculated from wind speed at measurement height, assuming a logarithmic wind profile. Variation in wind speed over the dispersal season and in terminal velocity values for different seeds can be accounted for by seasonally integrating the WALD model to determine a two-dimensional radial dispersal kernel. The kernel can be marginalized to estimate the median spread rate in one dimension by simulating a large number (here 10000) of dispersal distances, $r$, using the seasonally integrated model with associated random angles, $\alpha$, from a uniform distribution of angles from $0-2 \pi$ and calculating $x=r \cos (\alpha)$ (Lewis et al. 2006, Jongejans et al. 2008).

Spread rates were calculated for all possible combinations of the effects of $R$. conicus herbivory over the range of $0-15$ cysts per capitulum on seed production, release, and terminal velocity to examine which effects were most important in determining the calculated spread rates. The effects of $R$. conicus damage on seed release and dispersal were assumed to be the same for the U.S. and N.Z. populations for capitula of the same size. The mean of the probability density function for terminal velocity was treated as a function of cysts using fitted model output (Table 2). Terminal velocity values from the N.Z. population came from healthy $C$. nutans capitula unattacked by $R$. conicus collected on 3 April 2007 at the N.Z. site (Marchetto et al. 2010). Average numbers of cysts per capitulum come from experimental plants in Pennsylvania, USA (Z. Sezen, unpublished data), and naturalized plants near Argyll, New Zealand (Shea and Kelly 1998).

\section{RESULTS}

Total seed production was significantly negatively correlated with the number of $C$. nutans cysts per capitulum ( $P<0.001$, GLM; Fig. 1A, Table 2). Capitula with more cysts had a significantly higher proportion of seeds trapped in receptacle tissue $(P<$ 0.001, GLM; Fig. 1B, Table 2). Support for this effect on seed release is given by the fact that capitula with more cysts had lower seed release during wind tunnel trials $(P<0.001$, GLM; Fig. 1, Table 2$)$ designed to mimic strong, turbulent winds in the field (Jongejans et al. 2007). Furthermore, when capitula had more cysts, the terminal velocity of intact seeds was higher $(P<$ 0.001, LME; Fig. 1C, Table 2), meaning that seeds fall more quickly and disperse less far under given environmental conditions. Seeds from heavily attacked capitula were lighter $(P<0.001$, GLM), which would generally reduce seed terminal velocity (Greene and Johnson 1990), but this effect was more than offset by a reduction in pappus plume area $(P<0.001$, GLM $)$. Weevil damage was projected to reduce median dispersal 

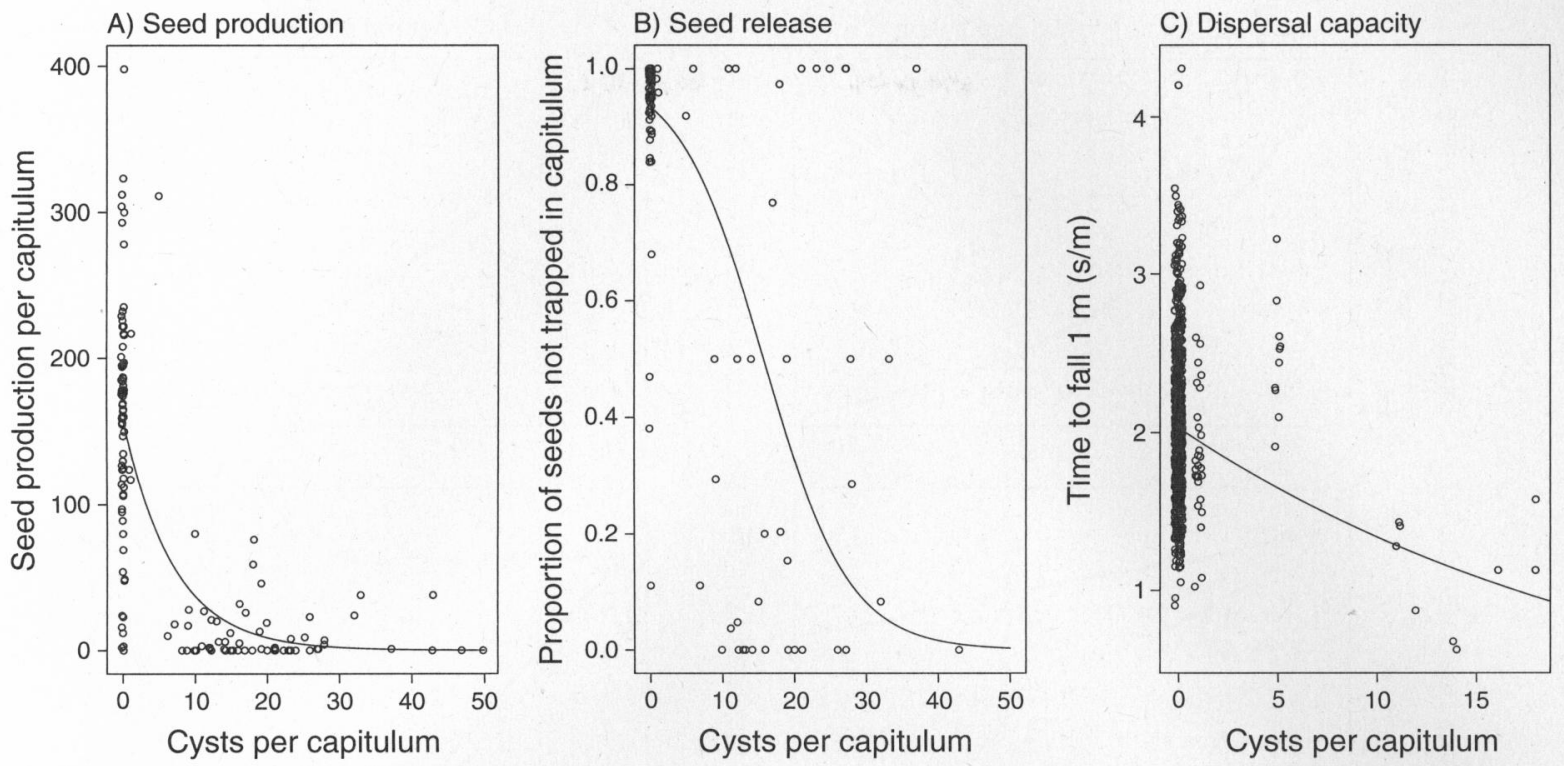

FIG. 1. Hierarchical effects of Rhinocyllus conicus damage on Carduus nutans seed dispersal and spread in the United States population. Here, herbivory is measured as the number of cysts (larval chambers) per capitulum. With an increasing number of larval cysts, (A) C. nutans seed production is reduced, (B) the produced seeds are less likely to be released from capitula, and (C) those that are released take less time to fall $1 \mathrm{~m}$ (terminal velocity ${ }^{-1}$ ) and therefore disperse less far on average. Panels show fitted trend lines from panels (A) a Poisson generalized linear model (GLM) with overdispersion correction, (B) a binomial GLM, and (C) a linear mixed-effects model that also includes capitulum of origin as a random effect. Cyst values were jittered around their integer values to indicate sample size.

distances by $32 \%$ from $1.7 \mathrm{~m}$ in the U.S. population and by $11 \%$ from $1.3 \mathrm{~m}$ in the N.Z. population (Appendix B: Fig. B1; percentage reductions are at the observed average of 7.0 cysts per capitulum in the USA and 2.5 in New Zealand).

The relative effects of $R$. conicus damage on reductions in projected $C$. nutans population growth rates and spread rates varied between sites. The observed average numbers of cysts per capitulum in the U.S. and N.Z. populations yield realized reductions in population growth rates of $64 \%$ and $17 \%$, respectively (Fig. 2). Current levels of weevil abundance cause estimated relative reductions in C. nutans population spread rates of $46 \%$ in the U.S. population and $43 \%$ in the N.Z. population (Fig. 2). Therefore, in the U.S. population $R$. conicus has a greater effect on $C$. nutans abundance than on spread, whereas in N.Z. it has a greater effect on spread than on abundance.

Different plant demography also affected the mechanisms most responsible for projected spread rate reductions. For the U.S. population growing under low competition, increased terminal velocity had the largest effect on population spread rates, but for the N.Z. population the largest effect was from reduction in seed production (Fig. 2). The number of seeds trapped in capitula did not greatly affect population spread rates for either population (Fig. 2), and the response to $R$. conicus attack was highly variable (Fig. 1).

\section{Discussion}

We show that a receptacle-feeding weevil, Rhinocyllus conicus, reduces the dispersal of Carduus nutans thistles through three mechanisms. $R$. conicus lowers seed production, reduces the proportion of intact seeds that release from capitula, and causes damage to seed dispersal structures so that the seeds drop more quickly in still air. Reductions in seed production and increases in seed terminal velocity combined had the greatest effect on projected median population spread rates, but the magnitude of each effect varied between sites that exhibit different plant demography. Increases in terminal velocity had the greatest impact on lowering projected population spread rates in the U.S. population, whereas reductions in seed production had the greatest effect in New Zealand. This may be because seed production by small plants greatly contributes to N.Z. population spread rates, while U.S. spread rates are sensitive to changes in terminal velocity (Jongejans et al. 2008, Shea et al. 2010). At the same time, $R$. conicus damage causes a larger decrease in population growth rates than spread rates in the U.S. population, but the opposite is true for the N.Z. population.

The effects of herbivory on plant population spread have two components: reducing seed production and influencing seed movement. These mechanisms are analogous to consumptive and nonconsumptive effects of predators. Theoretical work demonstrates that consumptive effects of predators can slow or even 

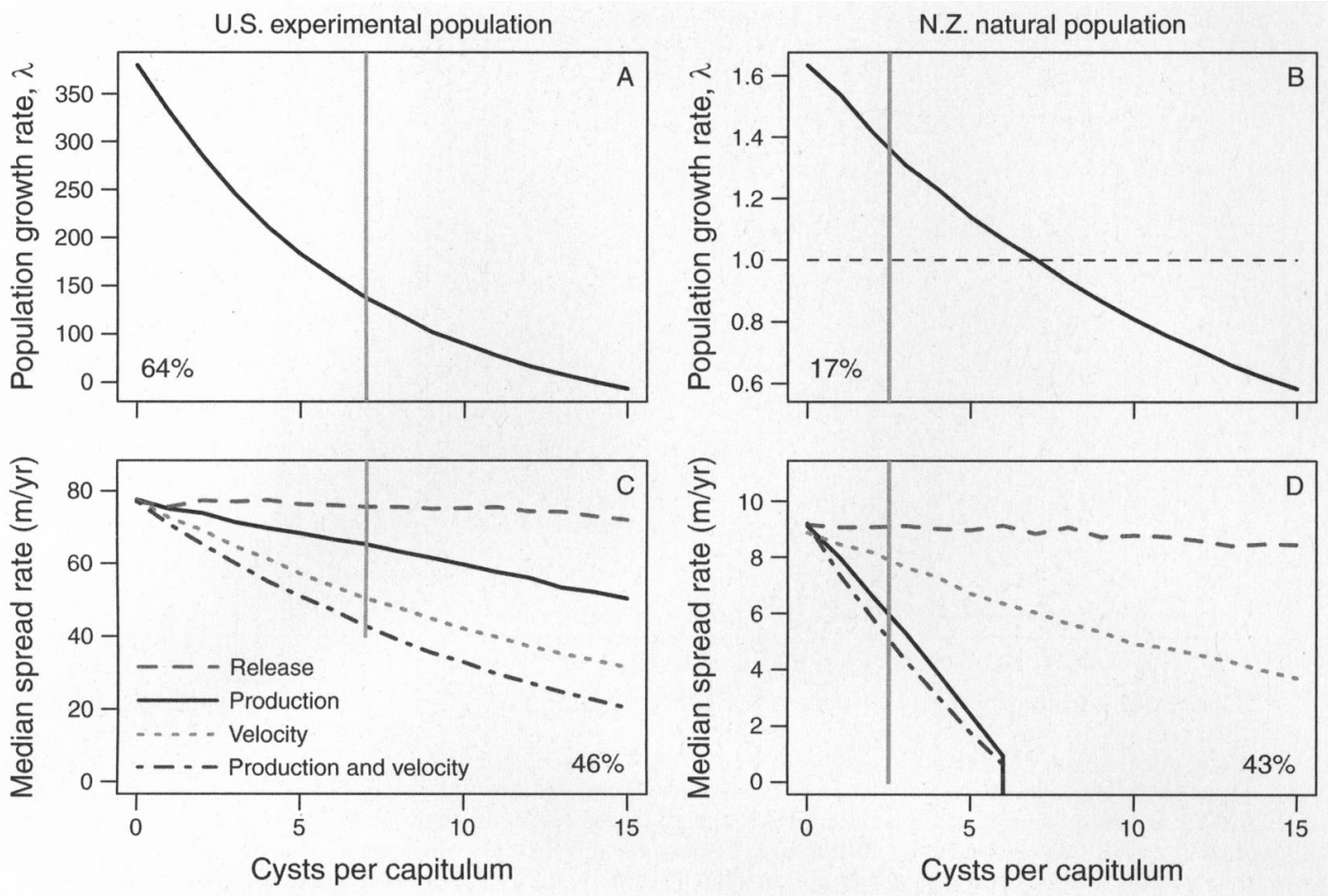

FIG. 2. Projected reductions in Carduus nutans median population growth and spread rates caused by Rhinocyllus conicus damage for an experimental population in the United States and a natural population in New Zealand. The key in panel (C) shows which model parameters are a function of cysts in each spread rate model for (C) the U.S. population and (D) the N.Z. population; release means seed release, production means seed production, velocity means terminal velocity. The U.S. population shows a $64 \%$ reduction in projected population growth rate $(\lambda)$ at the average number of cysts per capitulum (indicated by vertical lines; 7.0 in the USA and 2.5 in New Zealand), as opposed to a $46 \%$ reduction in projected median spread rates $\left(c^{*}\right)$, while the N.Z. population shows a $17 \%$ reduction in $\lambda$ and a $43 \%$ reduction in spread rate. Increases in seed terminal velocity have the greatest effect on $c^{*}$ in the U.S. population, but seed production matters more for the spread rate in New Zealand. The dashed horizontal line on panel B indicates when the N.Z. population growth rate becomes less than 1 (no spread).

reverse animal prey spread rates (Owen and Lewis 2001). In addition, predators have important nonconsumptive effects on the movement and spatial dynamics of their prey mediated by predator avoidance (Preisser et al. 2005, Ferrari et al. 2009). In plants, the nonconsumptive effect is via seed adhesion and pappus size, leading to altered seed movement characteristics; our results suggest that nonconsumptive effects may also play an important, but overlooked, role in the spatial dynamics of plants.

Reductions in seed dispersal caused by herbivores are likely not limited to the specific interaction between $R$. conicus and $C$. nutans. Herbivores can affect plant population spread rates with or without affecting seed production by changing the probability of seed release, terminal velocity, and plant height. We have shown that $R$. conicus has effects on dispersal of two related invasive thistles by reducing seed production and seed release in Carduus acanthoides (Appendix C) and by reducing seed production and causing premature detachment of entire capitula in Carduus pycnocephalus (Kelly et al. 1990). In addition, plant stunting caused by insect damage (Coombs et al. 2004) reduces plant height and therefore would likely reduce seed dispersal (Thomson et al.
2011). This height reduction effect has been documented in C. nutans, where a root feeder, Trichosirocalus horridus (Coleoptera: Curculionidae) reduced subsequent flowering height by $30 \%$ (Woodburn 1997).

These understudied antagonistic effects may differ in magnitude by location due to plant demographic traits. The same herbivore can have a greater effect on abundance of a plant in one population, while having a greater effect on spread in another. This same idea arises in the management of invasive species, where the same management strategy can lead to different outcomes depending on location (Shea et al. 2005). These context-dependent effects of a particular biocontrol agent highlight the need for land managers to first carefully identify the management objective, whether to focus control efforts on reducing abundance or spread, and then determine the most efficient management option to accomplish this goal (Shea et al. 2010).

We did not directly manipulate weevil herbivory in this study, which could possibly lead to some bias. Larger, primary capitula bloom first, and are therefore most likely to be attacked by weevils. Smaller capitula that bloom later in the season often receive less damage because they are not in phase with weevil phenology 


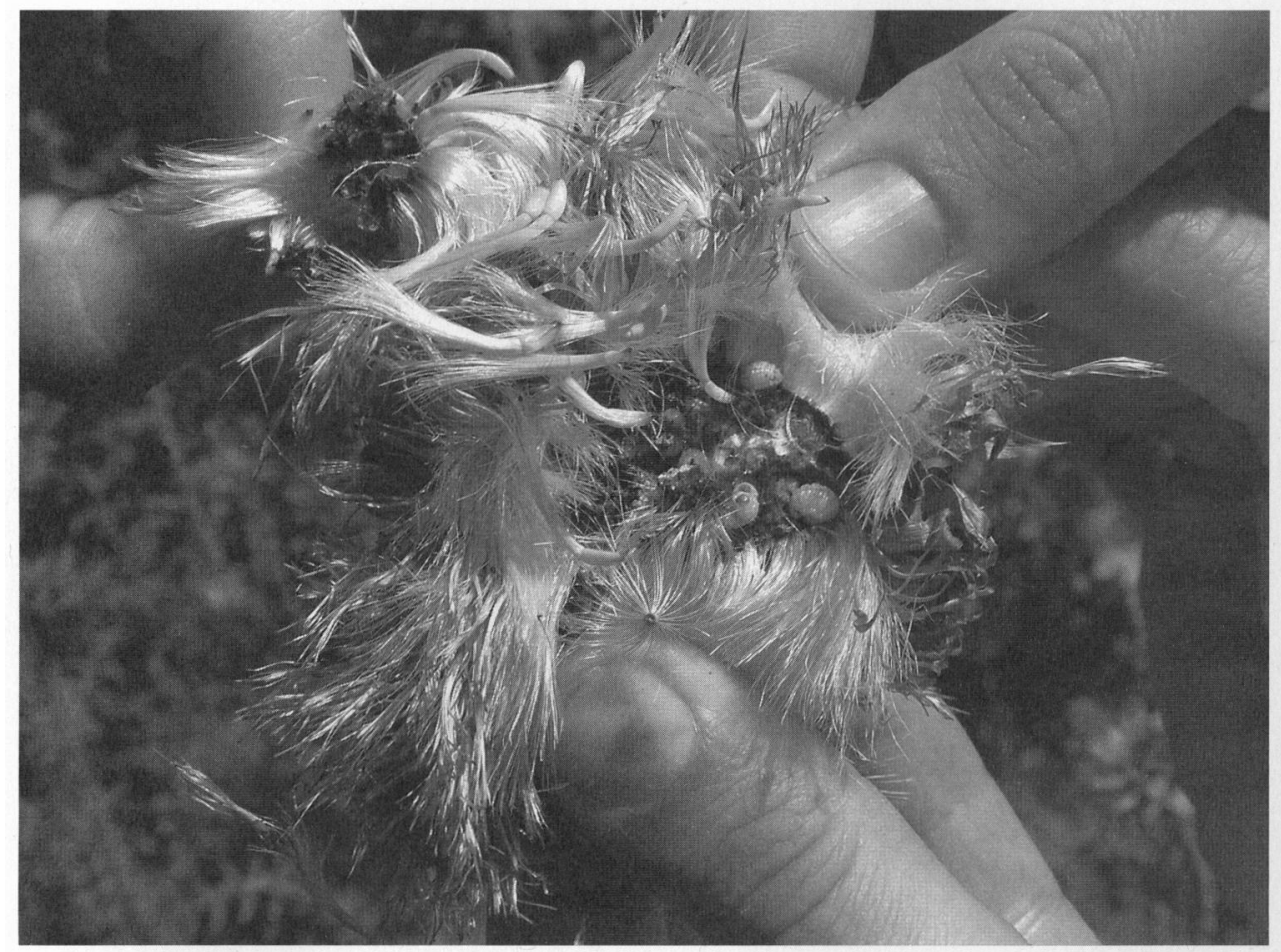

Plate 1. Rhinocyllus conicus larvae feeding on the receptacle tissue of a Carduus nutans flower head. Photo credit: Ottar Bjornstad.

(Kelly and Wood 1991). However, experimental manipulation of weevils is logistically challenging. Caging weevils on whole plants still will not control attack rates on individual capitula, while bagging weevils on to individual capitula alters temperature and moisture, which in turn affect larval and floral development.

Past assessments of biocontrol agent impacts have labeled $R$. conicus as a failure in New Zealand because weevil attack has not reduced $C$. nutans fecundity enough to cause population declines (Shea and Kelly 1998, Shea et al. 2005). However, R. conicus and other floral feeders may still be providing benefits through lower dispersal, in addition to any benefits through lower plant density (Kelly and McCallum 1995), because preventing invasive species from spreading to new areas is the most cost effective strategy for longterm control (DiTomaso 2000). In addition, low density thistle patches and those at an expanding wave front may not be immune to weevil attack. $R$. conicus attack rates are independent of local plant density, and these weevils have been observed to travel almost a kilometer, $940 \mathrm{~m}$, to find a host (Sezen 2007).

Assessment of potential biocontrol agents should include assessment of potential impacts on spread. The effect of biocontrol agents on plant dispersal traits can be measured in quarantined populations, and the effects on spread can be modeled before biocontrol agent release. Assessments should include nontarget effects; for example, $R$. conicus larvae are known to feed on native U.S. thistles (Louda et al. 1997) and may affect their dispersal also.

In conclusion, it is not enough to know how many viable seeds are produced in the presence of herbivores; we should also examine the effects of herbivore damage on release and dispersal of these seeds. This aspect of seed dispersal is nearly completely overlooked in studies of spread, hence current models may overestimate seed dispersal distances and spread rates for some species when antagonists are present. This can have ramifications for understanding the spatial ecology of plant populations, for projecting spread rates of invasive species, for predicting effects of climate change on plant species (Nathan and Muller-Landau 2000, Levin et al. 2003, Thomas et al. 2004), and for assessing the economic benefits of biological control programs.

\section{ACKNOWLEDGMENTS}

This research was funded by the National Science Foundation (NSF grants DEB-0315860 and DEB-0614065 awarded to K. Shea and an REU to K. M. Marchetto), the Netherlands Organisation for Scientific Research (NWO meerwaarde-grant 840.11 .001 to E. Jongejans), and the New Zealand Ministry of Business, Innovation, and Employment under the Outsmarting Weeds program, contract no. C10X0318. The Penn State Aerospace Engineering Department and R. Auhl provided the use of the wind tunnel. We also thank Penn State's High Performance Computing Group, O. Bjørnstad, M. Ferrari, B. Grenfell, H. de Kroon, S. Isard, D. Mortensen, L. Russo, A. Sheppard, S. Yang, and R. Zhang for technical assistance and helpful discussions. Many Shea lab undergraduates and $\mathbf{P}$. Marchetto helped with the empirical research. 


\section{Literature Cited}

Allen, M., and K. Shea. 2006. Spatial segregation of congeneric invaders in Pennsylvania, USA. Biological Invasions 8:509521.

Borowicz, V. A. 1988. Do vertebrates reject decaying fruit? An experimental test with Cornus amomum fruits. Oikos 53:7478.

Coombs, E. M., J. K. Clark, G. L. Piper, and J. A. F. Cofrancesco, editors. 2004. Biological control of invasive plants in the United States. Oregon State University Press, Corvallis, Oregon, USA.

Coutts, S., R. van Klinken, H. Yokomizo, and Y. Buckley. 2011. What are the key drivers of spread in invasive plants: dispersal, demography or landscape: and how can we use this knowledge to aid management? Biological Invasions 13:1649-1661.

Crawley, M. J. 2007. The R book. John Wiley and Sons, Chichester, UK.

Debach, P. 1974. Biological control by natural enemies. Cambridge University Press, New York, New York, USA.

Delfosse, E. S. 2005. Risk and ethics in biological control. Biological Control 35:319-329.

Desrochers, A. M., J. F. Bain, and S. I. Warwick. 1988. The biology of Canadian weeds. 89. Carduus nutans L. and Carduus acanthoides L. Canadian Journal of Plant Science 68:1053-1068.

DiTomaso, J. M. 2000. Invasive weeds in rangelands: species, impacts, and management. Weed Science 48:255-265.

Eilenberg, J., A. Hajek, and C. Lomer. 2001. Suggestions for unifying the terminology in biological control. Biocontrol 46:387-400.

Fagan, W. F., M. Lewis, M. G. Neubert, C. Aumann, J. L. Apple, and J. G. Bishop. 2005. When can herbivores slow or reverse the spread of an invading plant? A test case from Mount St. Helens. American Naturalist 166:669-685.

Ferrari, M. C. O., A. Sih, and D. P. Chivers. 2009. The paradox of risk allocation: a review and prospectus. Animal Behaviour 78:579-585.

Gassmann, A., and S. M. Louda. 2001. Rhinocyllus conicus: initial evalutation and subsequent ecological impacts in North America. Pages 147-183 in E. Wajnberg, J. K. Scott, and P. C. Quimby, editors. Evaluating indirect ecological effects of biological control. CABI Publishing, Wallingford, Oxon, UK.

Greene, D. F., and E. A. Johnson. 1990. The aerodynamics of plumed seeds. Functional Ecology 4:117-125.

Jessep, C. 1989. Carduus nutans L., nodding thistle (Asteraceae). Pages 339-342 in P. Cameron, R. Hill, J. Bain, and W. Thomas, editors. A review of biological control of invertebrate pests and weeds in New Zealand 1874 to 1987. CABI Publishing, Wallingford, Oxon, UK.

Jongejans, E., N. M. Pedatella, K. Shea, O. Skarpaas, and R. Auhl. 2007. Seed release by invasive thistles: the impact of plant and environmental factors. Proceedings of the Royal Society B 274:2457-2464.

Jongejans, E., K. Shea, O. Skarpaas, D. Kelly, A. W. Sheppard, and T. L. Woodburn. 2008. Dispersal and demography contributions to population spread of Carduus nutans in its native and invaded ranges. Journal of Ecology 96:687-697.

Katul, G. G., A. Porporato, R. Nathan, M. Siqueira, M. B. Soons, D. Poggi, H. S. Horn, and S. A. Levin. 2005. Mechanistic analytical models for long-distance seed dispersal by wind. American Naturalist 166:368-381.

Kelly, D., and K. McCallum. 1995. Evaluating the impact of Rhinocyllus conicus on Carduus nutans in New Zealand. Pages 205-211 in Proceedings of the 8th International Symposium on Biological Control of Weeds. DSIR/CSIRO, Lincoln University, Canterbury, New Zealand.

Kelly, D., K. McCallum, C. J. Schmidt, and P. Scanlan. 1990. Seed predation in nodding and slender winged thistles by nodding thistle receptacle weevil. Pages $212-215$ in A. J. Popay, editor. Proceedings of the 43rd New Zealand Weed and Pest Control Conference. The New Zealand Weed and Pest Control Society, Dunedin, New Zealand.

Kelly, D., and A. I. Popay. 1985. Pasture production lost to unsprayed thistles at two sites. Pages 115-118 in M. J. Hartley, editor. Proceedings of the 38th New Zealand Weed and Pest Control Conference. The New Zealand Weed and Pest Control Society, Rotorua, New Zealand.

Kelly, D., and R. Wood. 1991. Why hodding thistle receptacle weevil destroys so little seed in Canterbury. Pages 280-283 in A. J. Popay, editor. Proceedings of the 44th New Zealand Weed and Pest Control Conference. The New Zealand Weed and Pest Control Society, Tauranga, New Zealand.

Kolb, A., J. Ehrlen, and O. Eriksson. 2007. Ecological and evolutionary consequences of spatial and temporal variation in pre-dispersal seed predation. Perspectives in Plant Ecology, Evolution and Systematics 9:79-100.

Le Maitre, D. C., R. M. Krug, J. H. Hoffmann, A. J. Goydon, and T. N. Mgidi. 2008. Hakea sericea: development of a model of the impacts of biological control on population dynamics and rates of spread of an invasive species. Ecological Modelling 212:342-358.

Levin, S. A., H. C. Muller-Landau, R. Nathan, and J. Chave. 2003. The ecology and evolution of seed dispersal: a theoretical perspective. Annual Review of Ecology, Evolution, and Systematics 34:575-604.

Lewis, M. A., M. G. Neubert, H. Caswell, J. S. Clark, and K. Shea. 2006. A guide to calculating discrete-time invasion rates from data. Pages 169-192 in M. W. Cadotte, S. M. McMahon, and T. Fukami, editors. Conceptual ecology and invasion biology: reciprocal approaches to nature. Springer, Dordrecht, The Netherlands.

Louda, S. M., D. Kendall, J. Connor, and D. Simberloff. 1997. Ecological effects of an insect introduced for the biological control of weeds. Science 277:1088-1090.

Marchetto, K. M., E. Jongejans, M. L. Jennis, E. M. Haner, C. T. Sullivan, D. Kelly, and K. Shea. 2010. Shipment and storage effects on the terminal velocity of seeds. Ecological Research 25:83-92.

Marchetto, K. M., E. Jongejans, K. Shea, and R. Auhl. 2012. Water loss from flower heads predicts seed release in two invasive thistles. Plant Ecology and Diversity 5:57-65.

Maron, J. L., and E. Crone. 2006. Herbivory: effects on plant abundance, distribution and population growth. Proceedings of the Royal Society B 273:2575-2584.

Meyer, S. E., and S. L. Carlson. 2001. Achene mass variation in Ericameria nauseosus (Asteraceae) in relation to dispersal ability and seedling fitness. Functional Ecology 15:274-281.

Nathan, R., and H. C. Muller-Landau. 2000. Spatial patterns of seed dispersal, their determinants and consequences for recruitment. Trends in Ecology and Evolution 15:278-285.

Neubert, M. G., and H. Caswell. 2000. Demography and dispersal: calculation and sensitivity analysis of invasion speed for structured populations. Ecology 81:1613-1628.

Owen, M. R., and M. A. Lewis. 2001. How predation can slow, stop, or reverse a prey invasion. Bulletin of Mathematical Biology 63:655-684.

Peterson-Smith, J., and K. Shea. 2010. Seedling emergence and early survival of Carduus spp. in three habitats with press and pulse disturbances. Journal of the Torrey Botanical Society 137:287-296. 
Preisser, E., D. Bolnick, and M. Benard. 2005. Scared to death? The effects of intimidation and consumption in predatorprey interactions. Ecology 86:501-509.

Sezen, Z. 2007. Interactions of the invasive thistle Carduus nutans and its biocontrol agent Rhinocyllus conicus in heterogeneous environments. Dissertation. Pennsylvania State University, University Park, Pennsylvania, USA.

Shea, K., E. Jongejans, O. Skarpaas, D. Kelly, and A. Sheppard. 2010. Optimal management strategies to control local population growth or population spread may not be the same. Ecological Applications 20:1148-1161.

Shea, K., and D. Kelly. 1998. Estimating biocontrol agent impact with matrix models: Carduus nutans in New Zealand. Ecological Applications 8:824-832.

Shea, K., D. Kelly, A. W. Sheppard, and T. L. Woodburn. 2005. Context-dependent biological control of an invasive thistle. Ecology 86:3174-3181.

Sheldon, J. C., and F. M. Burrows. 1973. The dispersal effectiveness of the achene-pappus units of selected Compositae in steady winds with convection. New Phytologist 72:665-675.

Shorthouse, J. D., and R. G. Lalonde. 1984. Structural damage by Rhinocyllus conicus (Coleoptera, Curculionidae) within the flowerheads of nodding thistle. Canadian Entomologist 116:1335-1343.

Skarpaas, O., R. Auhl, and K. Shea. 2006. Environmental variability and the initiation of dispersal: turbulence strongly increases seed release. Proceedings of the Royal Society B 273:751-756.

Skarpass, O., and K. Shea. 2007. Dispersal patterns, dispersal mechanisms and invasion wave speeds for invasive thistles. American Naturalist 170:421-430.

Smith, L. M., and L. T. Kok. 1984. Dispersal of musk thistle (Carduus nutans) seèds. Weed Science 32:120-125.
Surles, W. W., and L. T. Kok. 1978. Carduus thistle seed destruction by Rhinocyllus conicus. Weed Science 26:264269.

Swamy, V., and J. W. Terborgh. 2010. Distance-responsive natural enemies strongly influence seedling establishment patterns of multiple species in an Amazonian rain forest. Journal of Ecology 98:1096-1107.

Thomas, C. D., et al. 2004. Extinction risk from climate change Nature 427:145-148.

Thomson, F. J., A. T. Moles, T. D. Auld, and R. T. Kingsford. 2011. Seed dispersal distance is more strongly correlated with plant height than with seed mass. Journal of Ecology 99:1299-1307.

Vellend, M., T. M. Knight, and J. M. Drake. 2006. Antagonistic effects of seed dispersal and herbivory on plant migration. Ecology Letters 9:316-323.

Vilà, M., I. Bartomeus, A. C. Dietzsch, T. Petanidou, I. SteffanDewenter, J. C. Stout, and T. Tscheulin. 2009. Invasive plant integration into native plant-pollinator networks across Europe. Proceedings of the Royal Society B 276:3887-3893.

Vivian-Smith, G., C. R. Gosper, A. Wilson, and K. Hoad 2006. Lantana camara and the fruit- and seed-damaging fly, Ophiomyia lantanae (Agromyzidae): seed predator, recruitment promoter or dispersal disrupter? Biological Control $36: 247-257$

Waage, J. K., and N. J. Mills. 1992. Biological control. Pages 412-430 in M. J. Crawley, editor. Natural enemies: the population biology of predators, parasites, and diseases. Blackwell Scientific Publications, Oxford, UK.

Woodburn, T. L. 1997. Establishment in Australia of Trichosirocalus horridus a biological control agent for Carduus nutans, and preliminary assessment of its impact on plant growth and reproductive potential. Biocontrol Science and Technology 7:645-656.

\section{SuPplemental MATERIAL}

Appendix A

Detailed description of population spread rate model (Ecological Archives A024-068-A1).

\section{Appendix B}

Median Carduus nutans seed dispersal distances (Ecological Archives A024-068-A2).

\section{Appendix C}

Supporting empirical study of the effects of Rhinocyllus conicus on Carduus acanthoides (Ecological Archives A024-068-A3). 